\title{
VIOLÊNCIA SEXUAL CONTRA PESSOAS COM DEFICIÊNCIA NOS ÚLTIMOS 10 ANOS: UMA REVISÃO SISTEMÁTICA
}

\author{
VIOLENCIA SEXUAL CONTRA PERSONAS CON DISCAPACIDAD EN LOS \\ ÚLTIMOS 10 AÑNOS: UNA REVISIÓN SISTEMÁTICA
}

\author{
SEXUAL VIOLENCE AGAINST PEOPLE WITH DISABILITIES IN THE LAST 10 \\ YEARS: A SYSTEMATIC REVIEW
}

\author{
Marlon Jose Gavlik MENDES ${ }^{1}$ \\ Fátima Elisabeth DENARI ${ }^{2}$
}

\begin{abstract}
RESUMO: A violência sexual direcionada a pessoas com deficiência faz parte das diversas situações de violência reportada às autoridades e atendidas por profissionais da saúde, da educação e da assistência social. Este assunto desperta interesse de pesquisadores e pesquisadoras nacionais de diversas áreas do conhecimento. O objetivo deste artigo foi investigar a produção científica brasileira dos últimos dez anos a respeito da violência sexual direcionada a pessoas com deficiência. $\mathrm{O}$ método utilizado foi o da revisão sistemática de literatura. A base de dados selecionada foi o portal de periódicos da Capes. Encontrou-se 26 artigos no período de 2009 e 2019. A maioria destes artigos contou com pesquisas de campo em notificações de atendimentos hospitalares oriundos de violência, sendo que poucos artigos analisaram a incidência de violência sexual contra pessoas com deficiência. Por mais que ajam significativas pesquisas na área, ainda há temáticas relativas à violência sexual contra pessoas com deficiência a ser pesquisadas.
\end{abstract}

PALAVRAS-CHAVE: Violência sexual. Pessoa com deficiência. Revisão sistemática de literatura. Sexualidade. Educação.

RESUMEN: La violencia sexual dirigida a personas con discapacidad es parte de las diversas situaciones de violencia denunciadas y atendidas por profesionales de la salud, de la educación y de la asistencia social. Este tema despierta el interés de investigadores nacionales de diferentes áreas del conocimiento. El objetivo deste artículo fue investigar la producción científica brasileña de los últimos 10 años en relación a la violencia sexual dirigida a personas con discapacidad. El método utilizado fue la revisión sistemática de literatura. La base de datos seleccionada fue el portal de articulos Capes. Se encontraron 26 artículos en el periodo de 2009 a 2019. La mayoría de estos artículos tenían investigaciones de campo sobre notificaciones de visitas al hospital relacionadas con la violencia, con pocos artículos que analizaban la incidencia de violência sexual contra personas con discapacidad.

\footnotetext{
${ }^{1}$ Universidade Federal de São Carlos (UFSCAR), São Carlos - SP - Brasil. Doutorando no Programa de PósGraduação em Educação Especial do Departamento de Psicologia. ORCID: https://orcid.org/0000-0002-3473610X. E-mail: mgmgavlik@hotmail.com

2 Universidade Federal de São Carlos (UFSCAR), São Carlos - SP - Brasil. Professora Adjunta no Departamento de Psicologia e Professora no Programa de Pós-Graduação em Educação Especial. Doutorado em Metodologia do Ensino (UFSCAR). ORCID: https://orcid.org/0000-0001-9248-6359. E-mail: fadenari@terra.com.br
} 
Por mucho que haya una investigación significativa en el área, todavía hay cuestiones relacionadas con la violencia sexual contra las personas con discapacidad que deben investigarse.

PALABRAS CLAVE: Violencia sexual. Persona con discapacitad. Revisión sistemática de literatura. Sexualidad. Educación.

ABSTRACT: The sexual violence against people with disabilities are part of the various situations of violence reported to the authorities and attended by health, education, and social assistance professionals. This subject is part of the interest of national researchers from different areas of knowledge. The objective of this article was to investigate the Brazilian scientific production of the last 10 years regarding sexual violence against people with disabilities. The method used was the systematic literature review. The database selected was the Capes website. 26 articles were found in the period from 2009 to 2019. Most of these articles had field research on notifications of hospital visits related to violence, with only a few articles analyzing the incidence of sexual violence against people with disabilities. As much as there is significant research in the area, there are still issues related to sexual violence against people with disabilities to be researched.

KEYWORDS: Sexual violence. People with disabilities. Systematic literature review. Sexuality. Education.

\section{Introdução}

A violência sexual direcionada a pessoas com deficiência (PcD) faz parte das diversas situações de violência reportada às autoridades e atendidas por profissionais da saúde, da educação e da assistência social. O trabalho contra a violência sexual é diverso, envolvendo mapeamento de casos, atendimento de vítimas e programas de prevenção às violências e de discussão sobre sexualidade e gênero em variados ambientes, como a família e a escola.

A violência sexual pode ser entendida como:

[...] qualquer ato sexual, tentativa de obter um ato sexual, comentários inapropriados ou avanços de natureza sexual, além do tráfico sexual, realizados sem consentimento ou usando de coerção, sendo realizada por qualquer pessoa, independentemente de sua relação com a vítima, em qualquer situação, incluindo, mas não se limitando, a casa e ao trabalho (OMS, 2002, p. 149, tradução nossa). ${ }^{3}$

Qualquer ato sexual que envolva coerção, intimidação, ameaças ou chantagens, podendo ou não envolver penetração, toques e exposição e que seja realizado sem o

${ }^{3}[\ldots]$ any sexual act, attempt to obtain a sexual act, unwanted sexual comments or advances, or acts to traffic, or otherwise directed, against a person's sexuality using coercion, by any person regardless of their relationship to the victim, in any setting, including but not limited to home and work (OMS, 2002, p. 149). 
consentimento da outra pessoa é considerado um ato de violência sexual (OMS, 2002). A violência sexual contra crianças ou adolescentes é definida no contexto brasileiro como:

[...] todo ato ou jogo sexual com intenção de estimular sexualmente a criança ou o adolescente, visando utilizá-lo para obter satisfação sexual [...]. Pode ocorrer em uma variedade de situações como: estupro, incesto, assédio sexual, exploração sexual comercial, pornografia, pedofilia, manipulação de genitália, mamas e ânus, até o ato sexual com penetração, imposição de intimidades, exibicionismo, jogos sexuais e práticas eróticas não consentidas e impostas e "voyeurismo" (BRASIL, 2010, p. 29-30).

Dentro dos tipos de violência sexual, é comum encontrar incidência de exploração sexual e de estupro contra crianças e adolescentes. Exploração sexual, de acordo com o Fundo de População das Nações Unidas (UNFPA, 2018b), é o envolvimento forçado de crianças e adolescentes em atividades sexuais de prostituição, tráfico ou casamento forçado. O estupro é qualquer ato sexual, envolvendo ou não penetração, que é obtido a partir de coerção, constrangimento ou violência sem o completo consentimento de ambas as partes. Ambas estas violências sexuais são consideradas crimes passíveis de punição no território brasileiro segundo a Lei de Crimes Sexuais (BRASIL, 2009), além de serem classificadas como categorias de violência pela Organização Mundial da Saúde (OMS, 2002).

Especificamente sobre a violência sexual direcionada a pessoas com deficiência ${ }^{4}$, não há pesquisa nacional que forneça estatísticas explícitas sobre o número de vítimas de violência sexual segundo a Associação Brasileira para Ação por Direitos das Pessoas com Autismo (ABRAÇA, 2016), mas há pesquisas internacionais que demonstram grande incidência de violências contra esse público, principalmente contra mulheres e adolescentes do gênero feminino com deficiência intelectual. As mulheres com deficiência estão dez vezes mais vulneráveis e serem vítimas de violência sexual repetidamente. No caso da população masculina, homens com deficiência são quatro vezes mais vulneráveis do que homens sem tal diagnóstico (OMS, 2011; UNFPA, 2018a; 2018b).

Considerando a população mundial, estima-se que entre $40 \%$ a $68 \%$ das mulheres com deficiência tenha sofrido alguma situação de violência sexual até os 18 anos. Na população brasileira, há estimativa de que até $90 \%$ das mulheres com deficiência vivenciem algum estilo de violência sexual ao longo de sua vida (ABRAÇA, 2016).

${ }^{4}$ O Estatuto da Pessoa com Deficiência (BRASIL, 2015), define por pessoa com deficiência quem possui impedimentos físicos, mentais, intelectuais ou sensoriais que prejudiquem sua participação plena na sociedade. São os tipos de deficiência a deficiência física, intelectual, auditiva, visual e a múltipla deficiência. De acordo com o Censo de 2010 (BRASIL, 2012), mais de 45 milhões de brasileiros relatam possuir alguma deficiência. 
Mesmo não havendo pesquisas estatísticas realizadas em todo o território nacional que quantifiquem a incidência de violência sexual contra pessoas com deficiência, nota-se a existência de pesquisas que versam o tema. Devido a isso, o objetivo deste artigo foi investigar a produção científica brasileira dos últimos dez anos a respeito da violência sexual direcionada a pessoas com deficiência.

\section{Método}

A pesquisa realizada foi descritiva, de natureza qualitativa e sendo delineada a partir do método da revisão sistemática de literatura. Para Costa e Zoltowski (2014), a revisão sistemática ocorre através de procedimentos específicos: inicialmente formula-se um problema de pesquisa, para então se eleger os temas norteadores que serem pesquisados na literatura, que se convertem em operadores booleanos, enfim selecionando as bases de dados em que os temas serão pesquisados a partir dos operadores. Após esta busca inicial, os artigos encontrados passam por critérios de inclusão elencados pelos pesquisadores, podendo ser o ano de publicação, natureza do estudo, público atendido, entre outros, para então serem selecionados os artigos que irão compor a revisão sistemática (SAMPAIO; MANCINI, 2007).

O procedimento utilizado para esta pesquisa pode ser conferido na figura a seguir:

Figura 1 - Procedimento de revisão sistemática ${ }^{5}$

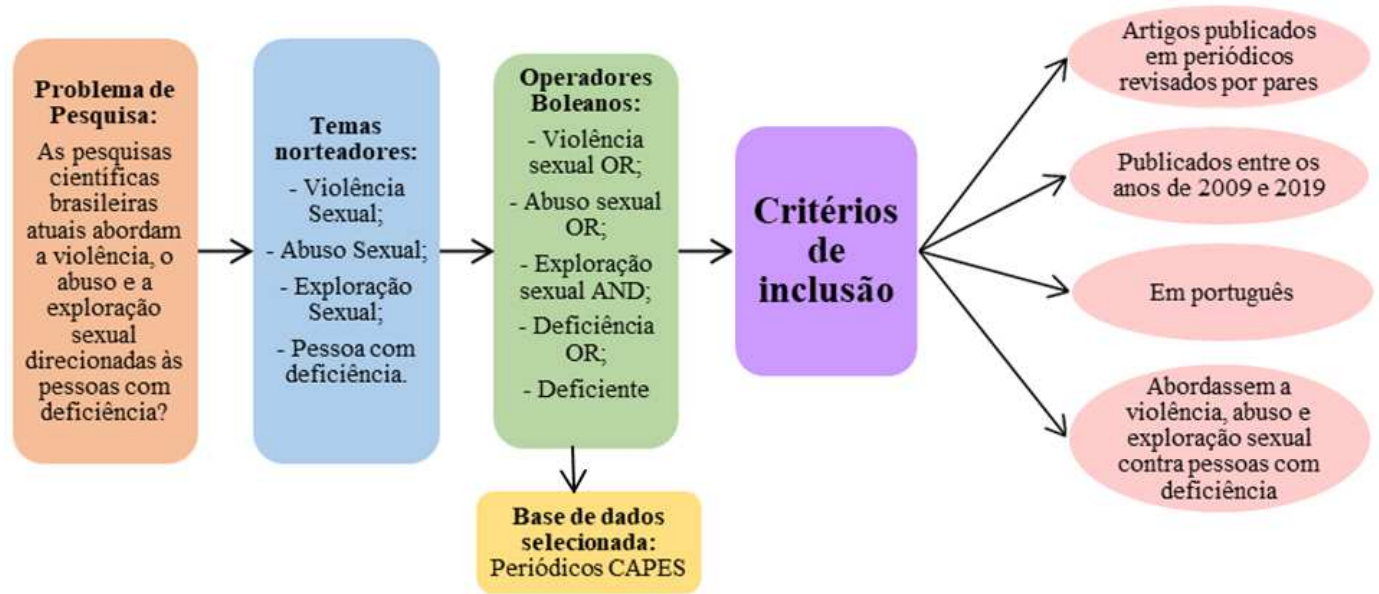

Fonte: Elaborado pelos autores

\footnotetext{
${ }^{5}$ Sanchez et al. (2019) propuseram repensar a utilização do termo "Abuso sexual" nas pesquisas cientificas, especialmente no que tange à violência sexual infantil. Para as autoras, o abuso significa o uso excessivo de algo ou alguém, mas, no caso de crianças e certas populações vulneráveis, não há a distinção de um uso excessivo e de um uso aceitável. Qualquer uso de seus corpos para obtenção de atos sexuais é considerado uma violência. Devido a isto, o termo abuso sexual não se encontra no corpo deste artigo, mas este foi mantido no processo de busca e nos critérios de seleção dos artigos pois ainda está presente nas pesquisas da atualidade.
} 
O processo de busca, seleção e inclusão dos artigos, pode ser conferido a seguir:

Figura 2 - Procedimento de busca e seleção dos artigos ${ }^{6}$
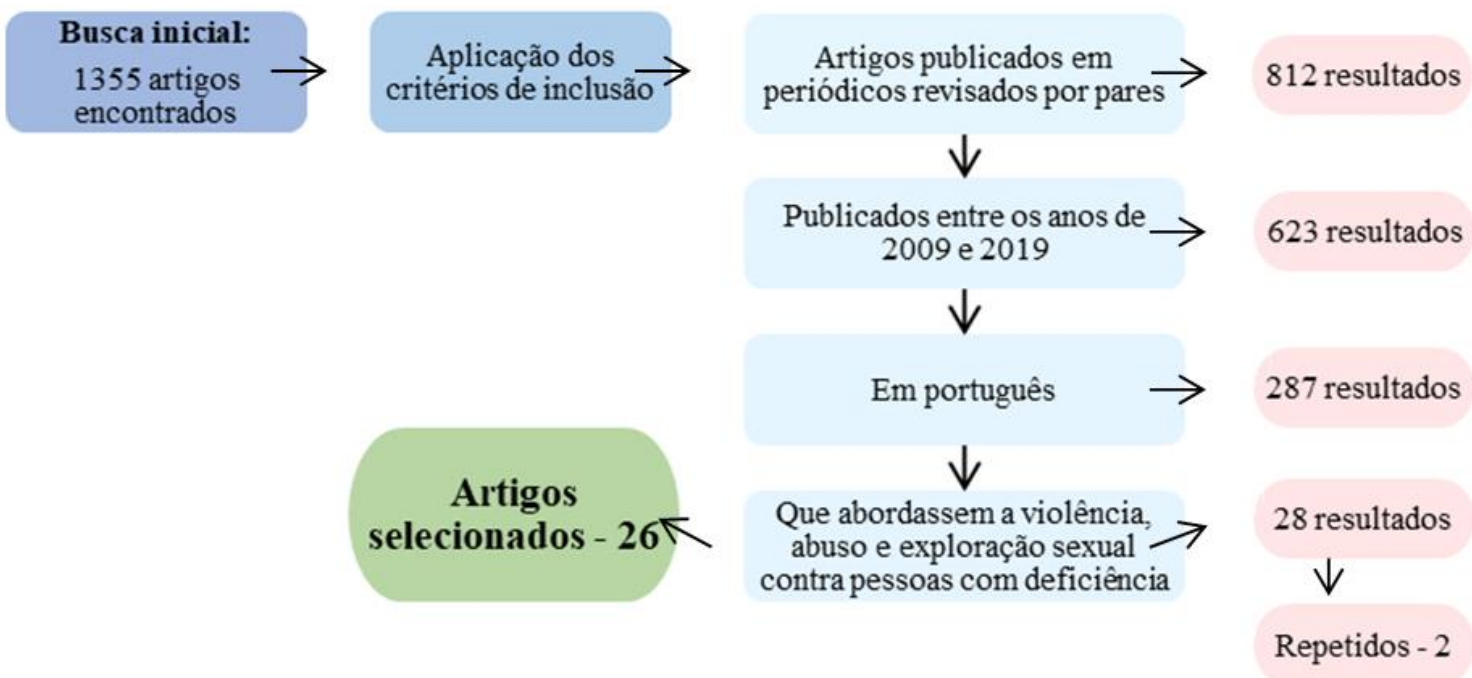

Fonte: Elaborado pelos autores

\section{Resultados e Discussão}

Analisando os 26 artigos pelo ano de publicação, é possível notar maior incidência de artigos publicados no ano de 2012, com seis artigos publicados, e nos anos de 2017 e 2016, com quatro em cada ano:

Figura 3 - Gráfico de distribuição dos artigos em relação ao ano da publicação

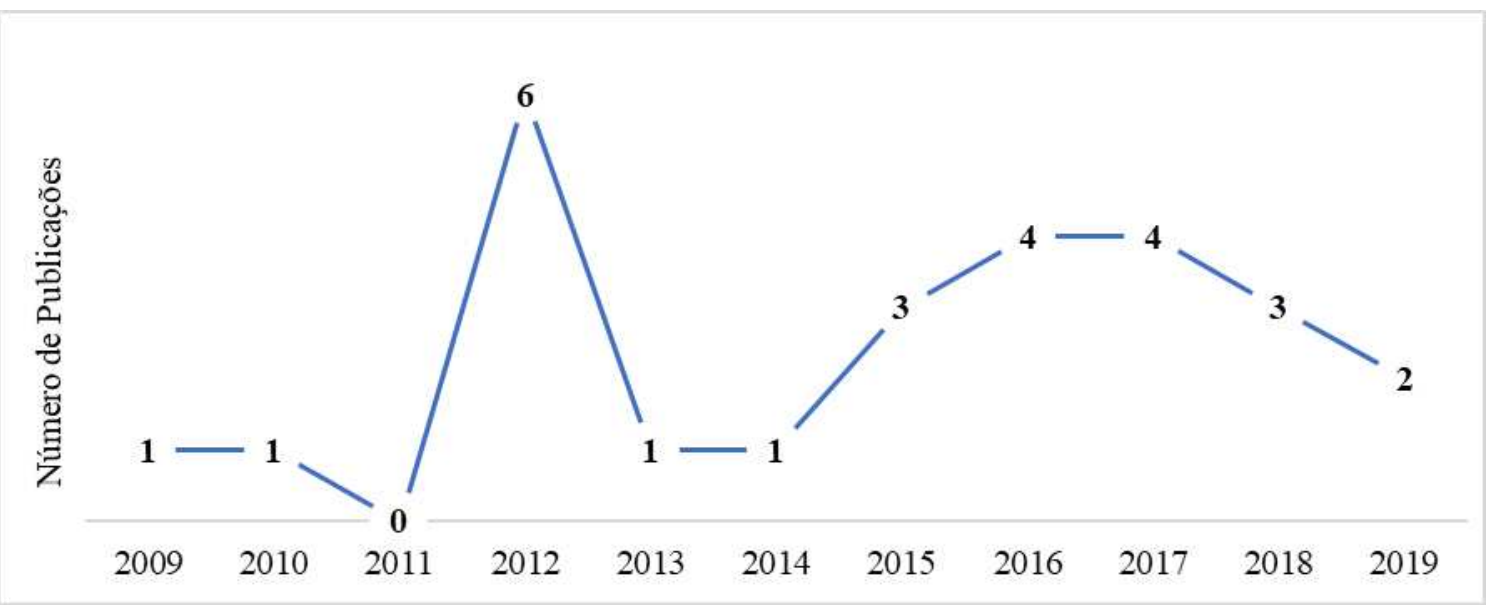

Fonte: Elaborado pelos autores 
Em relação às revistas em que os artigos foram publicados, encontrou-se maior concentração de artigos na revista Ciência e Saúde Coletiva:

Tabela 1 - Tabela de revistas e suas indexações ${ }^{7}$

\begin{tabular}{|c|c|c|}
\hline $\begin{array}{l}\text { Número } \\
\text { de Artigos }\end{array}$ & Revista & Principais Áreas de Indexação \\
\hline 15 & $\begin{array}{l}\text { Ciência e Saúde } \\
\text { Coletiva }\end{array}$ & $\begin{array}{l}\text { Administração Pública e de Empresas, Ciências Contábeis e Turismo - A2; Arquitetura, } \\
\text { Urbanismo e Design - A2; Ciência Política e Relações Internacionais - A2; Educação - } \\
\text { A2; Educação Física - A2; Ensino - A1; Psicologia - A2; Saúde Coletiva - B1; Serviço } \\
\text { Social - A1; Sociologia - A1. }\end{array}$ \\
\hline 2 & $\begin{array}{lr}\text { Physis: } & \text { Revista } \\
\text { de } & \text { Saúde } \\
\text { Coletiva } & \end{array}$ & $\begin{array}{l}\text { Administração Pública e de Empresas, Ciências Contábeis e Turismo - B1; Ciências } \\
\text { Ambientais - B1; Educação - B1; Enfermagem - A2; Interdisciplinar - B1; Psicologia - } \\
\text { A2; Planejamento Urbano e Regional / Demografia - B1; Psicologia - B1; Saúde Coletiva } \\
\text { - B1; Serviço Social - B1; Sociologia - B1. }\end{array}$ \\
\hline 1 & $\begin{array}{l}\text { Anuário } \\
\text { Antropológico }\end{array}$ & $\begin{array}{l}\text { Antropologia / Arqueologia - A2; Ciências Ambientais - B2; Direito - } \\
\text { Interdisciplinar - A2; Saúde Coletiva - C. }\end{array}$ \\
\hline 1 & $\begin{array}{l}\text { Revista } \\
\text { Brasileira em } \\
\text { Promoção } \\
\text { Saúde }\end{array}$ & $\begin{array}{l}\text { Administração Pública e de Empresas, Ciências Contábeis e Turismo - B2; Ensino - B1; } \\
\text { Psicologia - B1; Saúde Coletiva - B3; Serviço Social - B1. }\end{array}$ \\
\hline 1 & $\begin{array}{l}\text { Novos estudos } \\
\text { CEBRAP }\end{array}$ & $\begin{array}{l}\text { Administração Pública E De Empresas, Ciências Contábeis E Turismo - B1; Antropologia } \\
\text { / Arqueologia - A1; Ciência Política E Relações Internacionais - A2; Comunicação E } \\
\text { Informação - A2; Direito - A2; Filosofia - A2; História - A2; Interdisciplinar - } \\
\begin{array}{ll}\text { A2; Saúde Coletiva - B2; Sociologia - A2. } & \end{array}\end{array}$ \\
\hline 1 & $\begin{array}{l}\text { Revista Direito e } \\
\text { Práxis }\end{array}$ & Direito - A1; História - B1; Psicologia - B2; Saúde Coletiva - B4; Serviço Social - B2. \\
\hline 1 & $\begin{array}{l}\text { Jornal } \\
\text { Pediatria }\end{array}$ & $\begin{array}{l}\text { Biotecnologia - B1; Educação - A2; } \\
\text { Educação Física - A1; Enfermagem - B1; Engenharias IV - B1; Ensino - B2; Farmácia - } \\
\text { B1; Interdisciplinar - A2; Medicina I - B2; Nutrição - B1; Odontologia - B1; Psicologia - } \\
\text { A2; Saúde Coletiva - B1. }\end{array}$ \\
\hline 1 & $\begin{array}{l}\text { Revista de } \\
\text { Administração } \\
\text { Pública }\end{array}$ & $\begin{array}{l}\text { Administração Pública E De Empresas, Ciências Contábeis E Turismo - A2; } \\
\text { Arquitetura, Urbanismo E Design - A2; Ciência Política e Relações Internacionais - A1; } \\
\text { Direito - A2; Educação - B2; Psicologia - A2; Saúde Coletiva - B2; Sociologia - B1. }\end{array}$ \\
\hline 1 & $\begin{array}{l}\text { Revista Cogitare } \\
\text { de Enfermagem }\end{array}$ & $\begin{array}{l}\text { Administração Pública E De Empresas, Ciências Contábeis E Turismo - B2; Enfermagem } \\
\text { - B1; Interdisciplinar - B2; Psicologia - B2; Saúde Coletiva - B4. }\end{array}$ \\
\hline 1 & $\begin{array}{l}\text { Revista Estudos } \\
\text { Feministas }\end{array}$ & $\begin{array}{l}\text { Antropologia / Arqueologia - A1; Direito -A2; Educação - A1; Ensino - A2; História - A1; } \\
\text { Interdisciplinar - A1; Linguística e Literatura - A1; Psicologia - A2; Saúde Coletiva - B3; } \\
\text { Serviço Social - A2; Sociologia - A2; }\end{array}$ \\
\hline 1 & $\begin{array}{l}\text { Psicologia: } \\
\text { Teoria } \\
\text { Pesquisa }\end{array}$ & $\begin{array}{l}\text { Administração Pública e de Empresas, Ciências Contábeis E Turismo - B1; Direito - A1; } \\
\text { Educação - A1; Enfermagem - B1; Interdisciplinar - A1; Psicologia - A1; Saúde Coletiva - } \\
\text { B2; Sociologia - A2. }\end{array}$ \\
\hline
\end{tabular}

Fonte: Elaborado pelos autores

Analisando as revistas utilizadas para a publicação dos artigos nota-se que todas possuem indexação na área da saúde coletiva, demonstrando uma concordância com os apontamentos da OMS (2002) de que a violência sexual corresponde a um problema urgente de saúde pública. Também é notável o número de revistas com indexações na área da educação. Isso mostra que a violência sexual é um problema que não se deve limitar a apenas um campo de estudos ou de atuação, mas sim envolver trabalhos multidisciplinares e esforços

${ }^{7}$ Foi utilizada a Plataforma Sucupira para coletar dados a respeito das indexações das revistas. Disponível em: https://sucupira.capes.gov.br/sucupira/public/consultas/coleta/veiculoPublicacaoQualis/listaConsultaGeralPeriod icos.jsf. Acesso em: 25 mar. 2020. 
de diversos profissionais em todas as esferas da sociedade (POLANCZYK et al., 2003; VILAÇA, 2019).

Mesmo não presentes na revisão sistemática, no Brasil existem periódicos específicos com temas relacionados à violência sexual e a sexualidade, como a Revista Ibero-Americana de Estudos em Educação, vinculada à Universidade Estadual Paulista (UNESP) e ao primeiro curso brasileiro de pós-graduação stricto sensu em Educação Sexual da mesma universidade, e os Cadernos Pagu, revista vinculada à Universidade Estadual de Campinas (UNICAMP) e ao Núcleo de Estudos de Gênero Pagu.

Em relação à natureza da pesquisa realizada, foram encontrados quatro artigos teóricos, sete artigos que discutiram e analisaram políticas públicas e direitos das PcD e 15 pesquisas de campo. A distribuição dos artigos pode ser conferida a seguir:

Figura 4 - Gráfico de distribuição dos artigos em relação a natureza do estudo

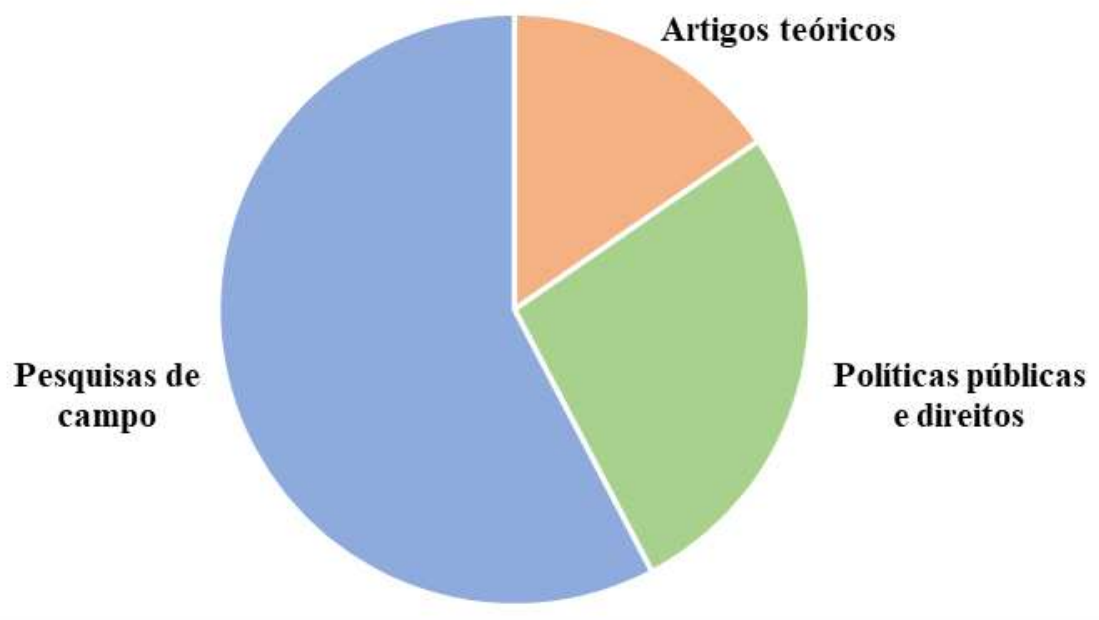

Fonte: Elaborado pelos autores

Adentrando os artigos teóricos, foram encontrados três ensaios e uma revisão integrativa de literatura. A caracterização destes artigos foi realizada no quadro a seguir:

Tabela 2 - Tabela de caracterização dos artigos teóricos

\begin{tabular}{|c|c|c|}
\hline $\begin{array}{c}\text { Autoria e } \\
\text { ano }\end{array}$ & Temas centrais & Principais conclusões $^{8}$ \\
\hline $\begin{array}{l}\text { Eickmann } \\
\text { et al. (2016) }\end{array}$ & $\begin{array}{l}\text { Diagnóstico de deficiências e } \\
\text { transtornos mentais em } \\
\text { crianças. }\end{array}$ & $\begin{array}{l}\text { Violência sexual é um fator estressante, junto com a pobreza extrema e as } \\
\text { doenças parentais. Se presentes por longos anos, causam a ativação } \\
\text { prolongada do sistema de resposta ao estresse na criança, diminuindo a } \\
\text { conectividade entre o córtex pré-frontal e o sistema límbico e prejudicando a } \\
\text { cognição. }\end{array}$ \\
\hline $\begin{array}{l}\text { Mello e } \\
\text { Nuerberg }\end{array}$ & $\begin{array}{l}\text { Intersecções entre estudos da } \\
\text { deficiência e os estudos de }\end{array}$ & $\begin{array}{l}\text { As mulheres com deficiência estão mais vulneráveis a situações de violência } \\
\text { sexual. }\end{array}$ \\
\hline
\end{tabular}


(2012) gênero.

Bisol e Estudos sobre a surdez. Ainda há assuntos inexplorados e poucos divulgados envolvendo a Sperb

(2010) comunidade surda, como a presença de violência sexual dentro da

Fonte: Elaborado pelos autores comunidade

Dentre os artigos teóricos, Tomaz et al. (2016) realizaram uma revisão integrativa de literatura de artigos e legislações brasileiras publicadas entre os anos de 2002 e 2012 que tratassem da saúde de pessoas com deficiência intelectual. Os autores selecionaram 15 artigos e 41 legislações. Especificamente sobre a violência sexual, os autores localizaram um artigo de 2009 que corresponde a um estudo de 53 casos de violência contra crianças e adolescentes, sendo $8,6 \%$ destes casos de violência sexual contra pessoas com deficiência intelectual, autismo ou transtorno mental. Os autores apontam a escassez de pesquisas sobre a violência sexual contra pessoas com deficiência intelectual.

Os artigos teóricos analisados demonstraram a vulnerabilidade de pessoas com deficiência a situações de violência sexual, em concordância com as discussões do Fundo de População das Nações Unidas (UNFPA, 2018a). A vulnerabilidade se estende principalmente a mulheres com deficiência, sendo que alguns autores hipotetizam as causas deste fenômeno:

O isolamento social, a dependência de educadoras/es, cuidadoras/es e prestadoras/es de serviços, o tipo de deficiência e o grau de funcionalidade associada à deficiência, a impossibilidade de defesa física de algumas pessoas com deficiência e diversos outros impedimentos à percepção e à reação diante do abuso levam a situações de maior risco desse grupo social (MELLO; NUERNBERG, 2012, p. 647).

Por outro lado, o ensaio realizado por Eickmann et al. (2016) mostra a violência sexual como antecedente e possível causa de deficiências intelectuais e transtornos mentais. Nota-se a relação dupla e retroativa que a deficiência e a violência mantêm entre si, possuir uma deficiência pode acarretar numa maior vulnerabilidade às situações de violência, assim como situações prolongadas de violência podem prejudicar o desenvolvimento físico e cognitivo, se desdobrando em deficiências. Tanto a deficiência quanto a exposição prolongada a situações de violência sexual são aqui entendidos determinantes sociais de saúde (SILVA et al., 2019), fatores que impactam diretamente na saúde e no bem-estar do indivíduo, o tornando mais sucintos a adoecimentos e, como discutido anteriormente, um ao outro.

Além dos artigos teóricos, foram encontrados sete artigos que discutiram as políticas públicas e os direitos relativos às pessoas com deficiência. A caracterização destes pode ser conferida a seguir: 
Tabela 3 - Tabela de caracterização dos artigos de legislação e políticas públicas

\begin{tabular}{|c|c|c|c|}
\hline Autoria & Objetivo & $\begin{array}{c}\text { Principais legislações } \\
\text { consultadas }\end{array}$ & Principais conc \\
\hline $\begin{array}{l}\text { Brandão } \\
\text { (2019) }\end{array}$ & $\begin{array}{l}\text { Discutir a } \\
\text { aplicabilidade de } \\
\text { métodos } \\
\text { anticoncepcionais } \\
\text { de emergência em } \\
\text { "populações } \\
\text { especiais" }\end{array}$ & $\begin{array}{l}\text { Portarias da Federação } \\
\text { Brasileira das Associações } \\
\text { de Ginecologia e } \\
\text { Obstetrícia }(2016,2017) \text { e } \\
\text { Pesquisa Nacional de } \\
\text { Demografia e Saúde da } \\
\text { Criança e da Mulher. PNDS } \\
\text { 2006: relatório final (2006). }\end{array}$ & $\begin{array}{l}\text { A consulta pública em } 2015 \text { sobre a inclusão dos } \\
\text { métodos de contracepção de emergência no SUS }{ }^{10} \text { foi } \\
\text { desfavorável, sendo decidido pela não inclusão. A } \\
\text { autora apontou o ocorrido como delicado, pois a } \\
\text { opinião pública desconsiderou discussões amplas sobre } \\
\text { gênero e sexualidade, responsabilizando apenas a } \\
\text { mulher pela contracepção. }\end{array}$ \\
\hline $\begin{array}{l}\text { Minayo et } \\
\text { al. (2018) }\end{array}$ & $\begin{array}{l}\text { Realizar } r \text { uma } \\
\text { reflexão sobre o } \\
\text { percurso histórico } \\
\text { do tema da } \\
\text { violência na saúde } \\
\text { pública }\end{array}$ & $\begin{array}{l}\text { Política nacional de redução } \\
\text { da morbimortalidade por } \\
\text { acidentes e violência } \\
\text { (2001); Sistema de } \\
\text { Vigilância de Violências } \\
\text { (2005) e Lei de crimes } \\
\text { sexuais (2009). }\end{array}$ & $\begin{array}{l}\text { A legislação brasileira obteve avanços nos últimos } \\
\text { anos, desde as definições de estupro e de violência } \\
\text { propostas pela Lei de Crimes Sexuais, até o controle de } \\
\text { notificações de casos de violência organizado pelo } \\
\text { Sistema de Vigilância de Violências. Ainda há pontos } \\
\text { que necessitam de maiores ações, como os sistemas de } \\
\text { informação relativos à violência, o atendimento } \\
\text { hospitalar de vítimas e a descentralização do serviço. }\end{array}$ \\
\hline $\begin{array}{l}\text { Jaccoud et } \\
\text { al. (2017) }\end{array}$ & $\begin{array}{l}\text { Analisar as } \\
\text { transformações } \\
\text { recentes no sistema } \\
\text { brasileiro de } \\
\text { proteção social }\end{array}$ & $\begin{array}{l}\text { Constituição } \quad r \text { Federal } \\
\text { Brasileira (1988); Lei } \\
\text { Orgânica da Assistência } \\
\text { Social (1993) e a Norma } \\
\text { Operacional Básica do } \\
\text { Sistema Unico da } \\
\text { Assistência Social (2005). }\end{array}$ & $\begin{array}{l}\text { A autora analisou a implementação do Sistema Único } \\
\text { de Assistência Social (SUAS) e suas diretrizes. O } \\
\text { atendimento de pessoas vítimas de violência sexual, } \\
\text { com e sem deficiências, pós } 1993 \text { corresponde a um } \\
\text { serviço de alta complexidade do sistema, sendo } \\
\text { atendido pelos Centros de referência especializada em } \\
\text { assistência social (CREAS) dos municípios. }\end{array}$ \\
\hline $\begin{array}{l}\text { Oliveira } \\
(2017)\end{array}$ & $\begin{array}{l}\text { Refletir sobre a } \\
\text { trajetória dos } \\
\text { movimentos } \\
\text { feministas no Brasil } \\
\text { com a aprovação da } \\
\text { Lei Maria Penha }\end{array}$ & Lei Maria da Penha (2006) & $\begin{array}{l}\text { A autora relata o caso de Maria da Penha, que adquiriu } \\
\text { deficiência física após ser vítima de violência pelo } \\
\text { marido. A autora também ressaltou a importância de } \\
\text { movimentos feministas, como a Convenção } \\
\text { Interamericana para Prevenir, Punir e Erradicar a } \\
\text { Violência contra a Mulher, de 1994, para a discussão } \\
\text { sobre as demandas envolvendo a erradicação da } \\
\text { violência sexual e doméstica direcionadas a mulheres } \\
\text { com e sem deficiências. }\end{array}$ \\
\hline $\begin{array}{l}\text { Nascimento } \\
\text { e Deslantes } \\
\text { (2016) }\end{array}$ & $\begin{array}{l}\text { Analisar a violência } \\
\text { sexual infanto- } \\
\text { juvenil, sua inclusão } \\
\text { e permanência na } \\
\text { agenda formal das } \\
\text { políticas nacionais }\end{array}$ & $\begin{array}{l}\text { Estatuto da Criança e do } \\
\text { Adolescente (1990); Lei } \\
\text { Orgânica da Assistência } \\
\text { Social (1993) e o Plano } \\
\text { nacional dos direitos da } \\
\text { criança e do adolescente } \\
(2010) \text {. }\end{array}$ & $\begin{array}{l}\text { A formulação de políticas públicas contra a violência } \\
\text { sexual infanto-juvenil no Brasil foi marcada por } \\
\text { pressão de grupos específicos que também assumiram } \\
\text { a função, junto com o poder público, de deliberar } \\
\text { políticas. Não é abordado a participação de PcD nessas } \\
\text { deliberações, mas elas também são alvo das políticas. }\end{array}$ \\
\hline $\begin{array}{l}\text { Moraes } \\
\text { Vitalle } \\
(2015)\end{array}$ & $\begin{array}{lr}\text { Descrever } & \text { os } \\
\text { documentos } & \\
\text { internacionais } & \text { e } \\
\text { nacionais } & \text { que } \\
\text { abordem os direitos } \\
\text { sexuais } \\
\text { reprodutivos } \\
\text { adolescência. }\end{array}$ & $\begin{array}{l}\text { Programa saúde do } \\
\text { adolescente (1989); Norma } \\
\text { Técnica de Prevenção e } \\
\text { Tratamento dos Agravos } \\
\text { Resultantes da Violência } \\
\text { Sexual contra Mulheres e } \\
\text { Adolescentes (1999) e a Lei } \\
\text { de Crimes Sexuais (2009). }\end{array}$ & $\begin{array}{l}\text { Foram analisadas } 10 \text { conferências da ONU junto com } \\
32 \text { documentos nacionais. Dentre os documentos, a Lei } \\
\text { do Estupro de Vulnerável aumentou a pena direcionada } \\
\text { ao ato de violência sexual contra crianças e } \\
\text { adolescentes com deficiência ( } 8 \text { a } 12 \text { anos de reclusão). } \\
\text { As autoras apontam avanços nas políticas de saúde } \\
\text { sexual, mas não debatem possíveis peculiaridades } \\
\text { envolvendo PcD }\end{array}$ \\
\hline $\begin{array}{l}\text { Cavalcante } \\
\text { e Ribeiro } \\
\text { (2012) }\end{array}$ & $\begin{array}{lr}\text { Desenvolver uma } \\
\text { avaliação dos } \\
\text { resultados da } \\
\text { implementação do } \\
\text { Sistema Único de } \\
\text { Assistência Social. }\end{array}$ & $\begin{array}{l}\text { Lei Orgânica da Assistência } \\
\text { Social (1993). }\end{array}$ & $\begin{array}{l}\text { Com as transformações propostas pela Lei Organiza da } \\
\text { Assistência Social, o cuidado as pessoas com } \\
\text { deficiência vítimas de violência passaram de ser } \\
\text { setorizado, em uma secretaria específica, para ser } \\
\text { considerado um serviço de alta complexidade, sendo } \\
\text { atendidos nos CREAS com as demais demandas desta } \\
\text { modalidade. }\end{array}$ \\
\hline
\end{tabular}

Fonte: Elaborado pelos autores

${ }^{9}$ No que tange à violência sexual direcionada a pessoas com deficiência.

${ }^{10}$ Sistema Único de Saúde. 
Um dos temas que foi amplamente discutido nos artigos foi o Sistema Único de Assistência Social (SUAS) e suas transformações, propostas pela Lei Orgânica da Assistência Social (BRASIL,1993). Dentre as mudanças no atendimento de pessoas com deficiência, este passou de ser realizado em um setor específico para ser considerado, dentro outros atendimentos, uma demanda de alta complexidade, demandando de equipe multiprofissional especializada e sendo realizado nos Centros de Referência Especializado de Assistência Social (CREAS) dos municípios. Esta mudança, como aponta Cardoso (2017), foi possibilitada pelas pressões sociais dos movimentos das pessoas com deficiência. Segundo a autora, dos anos 90 em diante houve um aumento do protagonismo das PcD nos movimentos sociais brasileiros, e uma das principais reivindicações foi a inclusão do público nos serviços regulares de educação, saúde e assistência. Estas pautas levaram a aproximação dos movimentos sociais das $\mathrm{PcD}$ a outros movimentos e a inclusão em diversos espaços.

Tanto o SUAS quanto o Sistema Único de Saúde (SUS), também presente nos artigos analisados, desenvolvem práticas de atendimento, prevenção e conscientização a respeito da violência sexual buscando a descentralização e o trabalho em redes integrais de cuidado (CAMPOS, 2018). Ambos os sistemas formam uma rede complexa de atendimentos, enquanto o SUS é o local dos primeiros cuidados que vítimas recebem após situações de violência, na modalidade de atendimento ambulatorial (VILLELA; LAGO, 2007), o SUAS é o local de realização de denúncias e atendimento multiprofissional subsequentes aos atendimentos médicos. Neste âmbito também são planejadas ações de prevenção, conscientização e combate à violência sexual; o que justifica o interesse de pesquisadores/as brasileiros/as de discutir estes sistemas e as legislações que os baseiam.

Além dos artigos teóricos e dos que discutiram políticas públicas, a maioria dos artigos encontrados constaram pesquisas de campo, sendo dois destes com pesquisas realizadas exclusivamente com pessoas com deficiência, nove realizadas também com pessoas com deficiências e quatro sem pessoas com deficiência, mas incluindo profissionais, pais e pessoas do convívio. A distribuição pode ser conferida no gráfico a seguir: 
Figura 5 - Gráfico da distribuição das pesquisas de campo pelos participantes

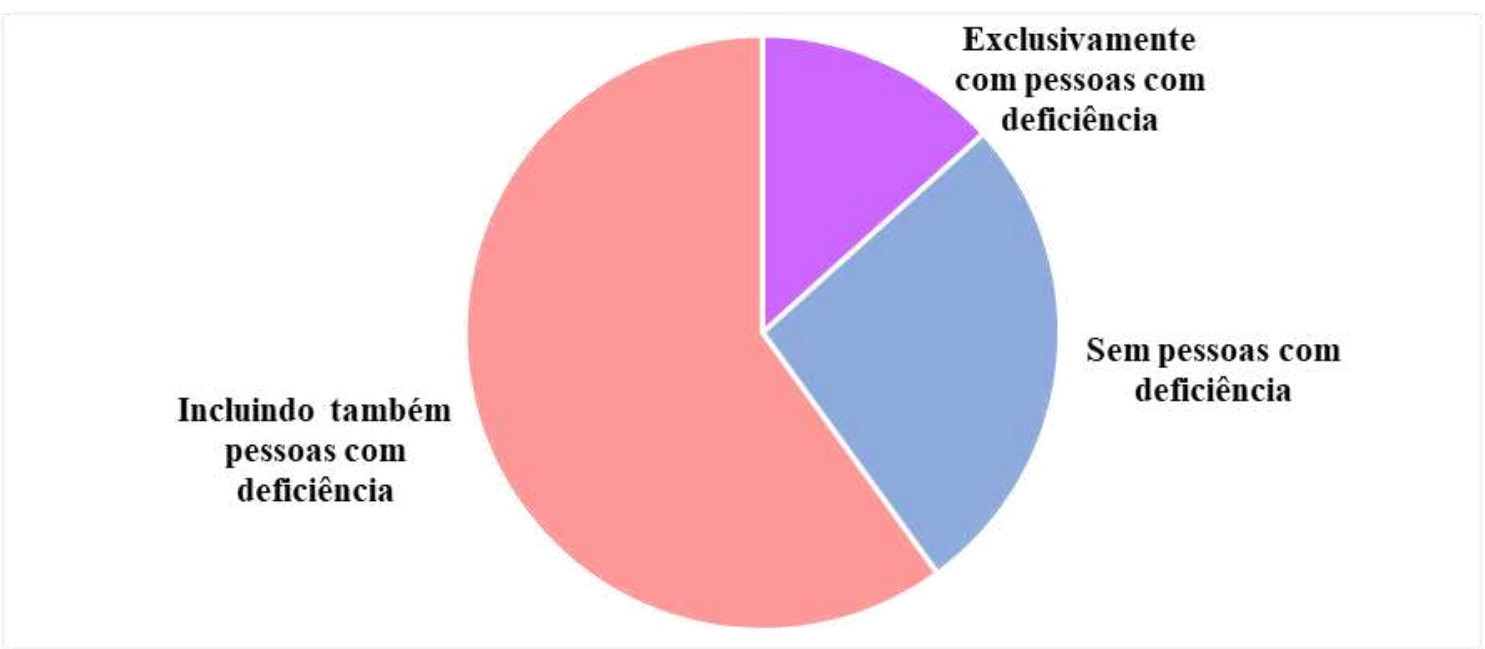

Fonte: Elaborado pelos autores

Os quatro artigos que continham pesquisas de campo que não envolveram pessoas com deficiência, mas envolveram pessoas do convívio de $\mathrm{PcD}$, familiares, profissionais, entre outros, abordaram a violência contra esse público de alguma maneira. A caracterização destes pode ser conferida a seguir:

Tabela 4 - Tabela de caracterização das pesquisas realizadas sem PcD




deficiência

vivenciam as

manifestações

sexuais de seus

filhos. intelectual

Teoria das Representaçõ -es Sociais Semiestruturada s e Grupos Operativos
Profissionais, gestores familiares de três instituições de violência sexual, os mesmos não são permitidos frequentar lugares sozinhos e conversar com estranhos. Esta proteção é mais intensa em meninas, com receios de gravidez indesejada e busca por métodos de contracepção e de esterilização. No caso dos meninos, os familiares interpretam a sexualidade como uma necessidade de seus filhos, e consideram utilizar de profissionais do sexo para que seus filhos aliviem seus desejos. Há o receio de que estes se tornem abusadores devido a seu intelecto e sua "sexualidade descontrolada".

Em uma instituição localizada em região controlada pelo tráfico de drogas ilícitas e com alto índice de violência, há incidência de violências contra a PcD no ambiente intrafamiliar e profissionais que ai atuam correm risco constante. Devido a isso, há uma cumplicidade dos profissionais em relação a violência que ocorre dentro de algumas famílias.

Fonte: Elaborado pelos autores

Aqui se percebe a multiplicidade de olhares frente a deficiência, se por um lado há famílias que superprotegem seus filhos, por outro a profissionais que entram em contato com famílias as quais causam ou são coniventes com situações de violência. A superproteção de familiares pode ocorrer, como afirmam Mendes e Denari (2019), devido aos mitos que envolvem a vivência da sexualidade pelas pessoas com deficiência. É comum os familiares verem seus filhos com deficiência como crianças desprovidas de sexualidade, os infantilizando, ou como pessoas com uma sexualidade exacerbada e descontrolada. Ambas as situações foram notadas no artigo de Bastos e Deslantes (2012), as filhas mulheres são vistas de maneira infantilizada e protegidas excessivamente por serem possíveis vítimas de violência sexual enquanto os filhos homens são tidos como descontrolados, podendo até se tornarem violentadores.

Os dois artigos que trouxeram pesquisas de campo realizadas exclusivamente com pessoas com deficiência trataram de estudos de caso de mulheres vítimas de violência sexual: 
Tabela 5 - Tabela de caracterização das pesquisas realizadas exclusivamente com PcD

\begin{tabular}{|c|c|c|c|c|}
\hline Autoria & Objetivo & Método & $\begin{array}{l}\text { Análise dos } \\
\text { dados }\end{array}$ & Participantes \\
\hline $\begin{array}{l}\text { Simões } \\
(2019)\end{array}$ & $\begin{array}{l}\text { Discutir as ambivalências do } \\
\text { conceito } \\
\text { intelectual' de 'deficiência } \\
\text { 'incapaz' e 'vulnerável' }\end{array}$ & Estudo de caso & $--^{11}$ & $\begin{array}{l}\text { Duas mulheres com deficiência } \\
\text { intelectual, } 13 \text { e } 27 \text { anos, } \\
\text { vítimas de violência sexual que } \\
\text { tiveram a a ação } \\
\text { interrompida. }\end{array}$ \\
\hline $\begin{array}{l}\text { Souto et } \\
\text { al. }(2012)\end{array}$ & $\begin{array}{l}\text { Caracterizar o perfil da vítima e } \\
\text { do agressor em casos de violência } \\
\text { sexual contra } \mathrm{PcD}\end{array}$ & $\begin{array}{l}\text { Estudo } \\
\text { transversal/Estudo } \\
\text { de caso }\end{array}$ & $\begin{array}{l}\text { Estatística } \\
\text { Descritiva }\end{array}$ & $\begin{array}{l}19 \text { mulheres com deficiência } \\
\text { intelectual vítimas de violência. }\end{array}$ \\
\hline
\end{tabular}

Fonte: Elaborado pelos autores

Os resultados de Souto et al. (2012) mostraram maior concentração de casos entre mulheres com idade de 12 a 19 anos, também entre 20 e 28 anos. A maioria das vítimas conhecia o agressor, sendo 12 agressores conhecidos, dois parceiros e um pai. 12 vítimas foram violentadas múltiplas vezes por um período superior a 20 dias e quatro foram ameaçadas verbalmente e fisicamente pelo agressor e coagidas a manter segredo. Já, os resultados de Simões (2019) apontam a pouca formação profissional para atendimento eficaz e humanizado de vítimas de violência, legislação ambígua e um demorado processo de interrupção da gravidez em casos de vítima de estupro.

Os resultados de Souto et al. (2012) se aproximam com os achados de Moreira et al. (2014) e Cavalcante e Minayo (2009) sobre os profissionais que atendem PcD, evidenciando a visibilidade dos casos de violência sexual praticada dentro do núcleo familiar.

Os artigos analisados estão em concordância com os artigos teóricos na questão da vulnerabilidade das $\mathrm{PcD}$, mulheres com deficiência são um dos públicos mais vulneráveis a situações de violência sexual. A alta incidência de violência contra este público, geralmente por familiares e outros conhecidos, com múltiplos episódios e acompanhada por ameaças e intimidações, assim como a dificuldade de atendimento após o episódio de violência e de interrupção da gravidez nos casos de gravidez indesejada mostra, como discutem Oliveira (2017) e Campos e Severi (2019), que discussões da saúde, do direito e da assistência no que tangem a violência sexual contra mulheres transcendem estudos meramente epidemiológicos e englobam discussões sociológicas, econômicas e epistemológicas. As relações sociais atuais e o desnível econômico entre os gêneros colocam mulheres, com e sem deficiências, mais suscetíveis a violências de todas as modalidades, incluindo a violência sexual:

[...] Como os direitos sexuais foram formulados a partir de sua negatividade, o exercício destes direitos indica que o aborto só pode ser realizado quando o 
bem jurídico da dignidade sexual, e não a própria pessoa, é violado. Assim, nos dois casos se faz uso de uma economia moral [...] em que dor, sofrimento e tristeza se convertem em uma linguagem mediante a qual o direito de interrupção de gravidez se converte em uma possibilidade (SIMÕES, 2019, p. 126-127)

A maioria das pesquisas de campo encontradas foram realizadas também com pessoas com deficiência, a caracterização dos nove artigos pode ser conferida a seguir:

Tabela 6 - Tabela de caracterização das pesquisas realizadas também com PcD

\begin{tabular}{|c|c|c|c|c|c|}
\hline Autoria & Objetivo & $\begin{array}{l}\text { Método de coleta } \\
\text { de dados }\end{array}$ & $\begin{array}{l}\text { Análise } \\
\text { dos } \\
\text { dados }\end{array}$ & $\begin{array}{c}\text { Fonte de } \\
\text { dados/ } \\
\text { Participantes }\end{array}$ & Resultados \\
\hline $\begin{array}{l}\text { Platt et al. } \\
(2018)\end{array}$ & \begin{tabular}{l}
\multicolumn{3}{l}{ Identificar } \\
características do \\
abuso sexual \\
contra crianças \\
no que tange a \\
vítimas \\
agressores
\end{tabular} & Análise estatística & $\begin{array}{l}\text { Estatística } \\
\text { Descritiva }\end{array}$ & $\begin{array}{ll}477 & \\
\text { notificações } & \text { do } \\
\text { Sistema } & \text { de } \\
\text { Informação } & \text { de } \\
\text { Agravos } & \text { de } \\
\text { Notificação } & \\
\text { (VIVA) } & \end{array}$ & $\begin{array}{l}75,5 \% \text { das notificações foram } \\
\text { contra crianças do sexo feminino } \\
\text { entre } 10 \text { e } 15 \text { anos. Maior } \\
\text { incidência de estupro contra o } \\
\text { sexo feminino e atentado violento } \\
\text { ao pudor contra or sexo } \\
\text { masculino. } 5,5 \% \text { dos casos foram } \\
\text { contra crianças com deficiência, } \\
\text { sendo } 20 \text { crianças do sexo } \\
\text { feminino e sete do sexo } \\
\text { masculino. }\end{array}$ \\
\hline $\begin{array}{l}\text { Avanci et al. } \\
\text { (2017) }\end{array}$ & \begin{tabular}{lr}
\multicolumn{2}{c}{ Analisar os dados } \\
de violência \\
intrafamiliar \\
atendidos \\
serviços & em \\
urgência & de \\
emergência & e
\end{tabular} & $\begin{array}{l}\text { Estudo } \\
\text { transversal/Análise } \\
\text { estatística }\end{array}$ & $\begin{array}{l}\text { Estatística } \\
\text { Descritiva }\end{array}$ & $\begin{array}{lr}4893 \quad \text { casos } \\
\text { notificados pelo } \\
\text { Sistema de } \\
\text { Vigilância } & \text { de } \\
\text { Acidentes } & \text { e } \\
\text { Violências } & \\
\text { (VIVA) } & \end{array}$ & $\begin{array}{l}413 \text { casos de violência crianças e } \\
\text { adolescentes, } 2,3 \% \text { destes contra } \\
\text { crianças e adolescentes com } \\
\text { deficiência. } 6.9 \% \text { das } \\
\text { notificações envolvendo crianças } \\
\text { do sexo feminino foram de } \\
\text { violência sexual. } 725 \text { casos de } \\
\text { violência intrafamiliar em } \\
\text { adultos, sendo que } 0,9 \% \text { destes } \\
\text { foram de violência sexual } \\
\text { direcionada a mulheres. }\end{array}$ \\
\hline $\begin{array}{l}\text { Souto et al } \\
(2017)\end{array}$ & \begin{tabular}{lr}
\multicolumn{2}{l}{ Descrever o perfil } \\
dos atendimentos \\
de & lesões \\
decorrentes & de \\
violência & em \\
serviços & de \\
urgência & e \\
emergência &
\end{tabular} & $\begin{array}{l}\text { Estudo } \\
\text { transversal/Análise } \\
\text { estatística }\end{array}$ & $\begin{array}{l}\text { Estatística } \\
\text { Descritiva }\end{array}$ & $\begin{array}{lr}4406 \quad \text { casos } \\
\text { notificados pelo } \\
\text { Sistema de } \\
\text { Vigilância } & \text { de } \\
\text { Acidentes } & \text { e } \\
\text { Violências } & \\
\text { (VIVA) } & \end{array}$ & $\begin{array}{l}125 \text { casos são de violência contra } \\
\text { pessoas com deficiência. } 51 \\
\text { casos foram de vítimas de } \\
\text { violência sexual ( } 41 \text { pessoas de } \\
\text { sexo feminino, } 10 \text { de sexo } \\
\text { masculino). }\end{array}$ \\
\hline $\begin{array}{l}\text { Malta et al. } \\
(2016)\end{array}$ & $\begin{array}{l}\text { Analisar os } \\
\text { atendimentos de } \\
\text { emergência } \\
\text { referentes às } \\
\text { causas externas }\end{array}$ & $\begin{array}{l}\text { Estudo } \\
\text { transversal/Análise } \\
\text { estatística }\end{array}$ & $\begin{array}{l}\text { Estatística } \\
\text { Descritiva }\end{array}$ & $\begin{array}{lr}424 \text { casos de } \\
\text { violência } & \\
\text { notificados pelo } \\
\text { Sistema rema } \\
\text { Vigilância } & \text { de } \\
\text { Acidentes } & \text { e } \\
\text { Violências } & \\
\text { (VIVA) } & \end{array}$ & $\begin{array}{l}1 \% \text { dos casos envolviam crianças } \\
\text { com deficiência, } 3,1 \% \text { dos casos } \\
\text { foram de violência sexual. Maior } \\
\text { concentração de violência em } \\
\text { crianças entre } 2 \text { e } 5 \text { anos. }\end{array}$ \\
\hline $\begin{array}{l}\text { Rates et al. } \\
\text { (2015) }\end{array}$ & $\begin{array}{l}\text { Analisar as } \\
\text { notificações de } \\
\text { violências contra } \\
\text { as crianças nos } \\
\text { serviços públicos } \\
\text { de saúde }\end{array}$ & $\begin{array}{l}\text { Estudo } \\
\text { descritivo/Análise } \\
\text { estatística }\end{array}$ & $\begin{array}{l}\text { Estatística } \\
\text { Descritiva }\end{array}$ & $\begin{array}{l}17900 \\
\text { notificações } \\
\text { pelo Sistema de } \\
\text { Vigilância de } \\
\text { Acidentes e } \\
\text { Violências } \\
\text { (VIVA) }\end{array}$ & $\begin{array}{l}660 \text { casos de violência contra } \\
\text { crianças com deficiência. } 5675 \\
\text { foram casos de violência sexual, } \\
\text { com maior prevalência crianças } \\
\text { entre } 6 \text { e } 9 \text { anos, do sexo } \\
\text { feminino e negras ou pardas. }\end{array}$ \\
\hline $\begin{array}{l}\text { Neves-Silva } \\
\text { et al. (2015) }\end{array}$ & $\begin{array}{l}\text { Investigar } \\
\text { barreiras } \\
\text { atitudinais } \\
\text { processo }\end{array}$ & $\begin{array}{l}\text { Entrevistas } \\
\text { semiestruturadas e } \\
\text { grupos focais }\end{array}$ & $\begin{array}{l}\text { Análise } \\
\text { do } \\
\text { Conteúdo }\end{array}$ & $\begin{array}{l}\text { Cinco PcD, } \\
\text { seus familiares } \\
\text { e } \quad 30 \\
\text { profissionais da }\end{array}$ & $\begin{array}{l}\text { O tema da violência sexual } \\
\text { surgiu como receio de um } \\
\text { familiar investigado em relação a } \\
\text { saída de seu filho ao mundo do }\end{array}$ \\
\hline $\begin{array}{l}\text { Dox: } \\
\text { DOI: }\end{array}$ & $10 x a \cdot v 2$ & 28 & 2021. & & $\begin{array}{r}\text { e-ISSN: } 2594-8385 \\
14\end{array}$ \\
\hline
\end{tabular}


ambiente de

trabalho

Nicolau et Identificar

al. (2013)

dimensões

individuais,

sociais

programáticas da

vulnerabilidade

de mulheres com

deficiência inclusão no

área

inclusão

da trabalho. $\mathrm{O}$ envolvimento familiar é imprescindível a boa inclusão da PcD em ambientes de trabalho.

Entrevistas $\quad--{ }^{12} \quad 15$ mulheres semiestruturadas

5 mulheres
com deficiência

As mulheres vivem um processo ambíguo de superproteção e de rejeição em suas famílias, causando pouca autonomia em suas vidas e uma rede social e de apoio escassa. Somando isso as construções sociais a respeito da deficiência e do papel da mulher na sociedade, as dificuldades do acesso e atendimento destas mulheres e os mitos em relação a sua sexualidade foi observado uma maior vulnerabilidade destas em relação as violências, inclusive a violência sexual.

Mascarenhas

Descrever as

Estudo notificações de violência contra descritivo/Análise estatística

$\begin{array}{ll}\text { Estatística } & 3593 \\ \text { Descritiva } & \text { notificações } \\ & \text { pelo Sistema de } \\ & \text { Vigilância de } \\ & \text { Acidentes e } \\ & \text { Violências } \\ & \text { (VIVA) }\end{array}$

(VIVA)
Assis et al. Descrever os (2012)

$\begin{array}{lr}\text { casos } & \text { de } \\ \text { violência } & \text { contra } \\ \text { crianças } & \end{array}$
crianças

\section{3}

notificações pelo Sistema de Vigilância de Acidentes Violências (VIVA)
538 casos de violência contra idosos com alguma deficiência, transtorno mental ou síndrome. 113 casos foram de violência sexual, sendo 96 contra mulheres. Há maior prevalência de violência sexual por pessoas que não são os filhos/as das vítimas com a presença do uso de álcool pelo agressor/a.

4457 casos de violência sexual entre crianças de um à nove anos (41,7\% das notificações) com maior incidência entre meninas e 120 casos contra crianças menores de um ano. Do número total, 405 dos casos correspondem a crianças com deficiência.

Fonte: Elaborado pelos autores

A maioria dos artigos analisados, sete no total, realizaram análises estatísticas das notificações de violência do Sistema de Vigilância de Acidentes e Violências (VIVA). O VIVA, segundo Assis et al. (2012), foi um marco importante para as políticas de controle e prevenção da violência, pois possibilitou a visualização da incidência da violência no território nacional servindo como base para estratégias de enfrentamento e estudos descritivos, como percebe-se nos artigos analisados. Sobre o sistema VIVA:

O Sistema de Vigilância de Violências e Acidentes (VIVA), implantado em 2006 pelo Ministério da Saúde, tem a finalidade de viabilizar a obtenção de dados e a divulgação de informações sobre violências e acidentes. O VIVA foi estruturado em dois componentes: o primeiro relacionado à vigilância contínua de violência doméstica, sexual e outras interpessoais e autoprovocadas (VIVA Contínuo); o outro componente, é a vigilância sentinela de violências e acidentes em emergências hospitalares (VIVA Sentinela). A partir de 2009, o componente de vigilância contínua do VIVA 
foi incorporado ao Sistema de Informação de Agravos Notificados (SinanNet), adequando-se as suas normas específicas no que se refere à padronização de coleta e envio de dados (ASSIS et al., 2012, p. 2306).

As pesquisas mostraram que as mulheres, tanto crianças e adolescentes quanto idosos, são mais vulneráveis à violência sexual. No que tange às pessoas com deficiência, as pesquisas mostraram a incidência de violência direcionada a elas, mas nenhum dos artigos discutiu a correlação direta entre possuir alguma deficiência e ter sido vítima de violência, nem comparou as porcentagens de vítimas de violência sexual entre as $\mathrm{PcD}$ e as pessoas sem deficiências, sendo temas que podem ser abordados em futuros estudos.

Platt et al. (2018) hipotetizam a maior vulnerabilidade das PcD a situações de violência sexual e a complexidade do atendimento destes casos visto a dificuldade de identificar os sintomas de crianças que passam por situações de violência em conjunto com as próprias limitações da deficiência. O tema da violência sexual surgiu na pesquisa de NevesSilva et al. (2015) como receio de familiares em relação ao convívio de seus filhos com deficiência na comunidade e no mundo do trabalho, como pode ser observado na fala de um familiar: "Eu tenho medo sim. Medo de acidente, cortar um dedo, cortar uma mão, abuso sexual, envolvimento com drogas, tudo isso aí desperta na gente um medo, um medo muito grande" (SILVA et al., 2015, p. 2553).

Sobre a violência sexual direcionada às crianças e adolescentes com deficiência, Assis et al. (2012, p. 2315) afirmam que:

\begin{abstract}
A maior sensibilização dos profissionais na atenção aos casos de violência sexual; a gravidade destes casos, que exigem a busca de atendimento pelo serviço de saúde; e a banalização da violência física contra a criança são algumas das justificativas para o maior número de notificações de abuso sexual pelo profissional de saúde, em comparação as outras violências.
\end{abstract}

O tema da vulnerabilidade das pessoas com deficiência, principalmente de mulheres, a situações de violência sexual emerge como um dos assuntos mais presentes nos artigos. Tema também discutido no artigo de Ottoni e Maia (2019) sobre sexualidade e o Transtorno do Espectro Autista (TEA). Tanto os artigos teóricos quanto as pesquisas de campo da revisão realizada apontam para maior fragilidade deste público, sendo que quando são vítimas de violência, como mostrou Souto et al. (2012), geralmente o episódio ocorre de maneira repetitiva, o agressor é alguém de família ou do convívio e ameaça/intimida a vítima para manter segredo. Todas as pesquisas de campo que realizaram análises estatísticas nas notificações de violência do sistema 'VIVA' averiguaram a presença de casos contra PcD, em sua maioria mulheres, mas nenhuma pesquisa comparou a prevalência de violência na 
população com deficiência em relação a população sem o diagnóstico de deficiência, averiguando se mulheres com deficiência realmente são mais vítimas do que mulheres sem tal diagnostico.

\section{Considerações finais}

Discutir a violência sexual direcionada às pessoas com deficiência é complexo, envolve noções teóricas da psicologia, sociologia e direito, englobando os campos da educação, saúde e assistência social. Este tema desperta interesse de pesquisadores e pesquisadoras brasileiros.

Analisando os artigos brasileiros publicados nos últimos dez anos que versam a temática, notou-se maior incidência de pesquisas de campo que realizaram análises estatísticas em notificações de violência direcionadas ao público geral, incluindo também as pessoas com deficiência. Em contraponto, há poucas pesquisas que investigaram exclusivamente as $\mathrm{PcD}$ e sua relação com o fenômeno da violência, enquanto nenhuma pesquisa comparou a incidência de violência em $\mathrm{PcD}$ em relação às pessoas sem diagnostico de deficiência.

Enquanto as pesquisas de campo trouxeram dados estatísticos sobre a incidência da violência, com algumas caracterizações sobre as vítimas e os agressores, as pesquisas que investigaram as políticas públicas trouxeram informações sobre o atendimento de vítimas de violência, tanto no âmbito da saúde quanto da assistência social. Por fim, os artigos teóricos circunscreveram estes temas tratando das concepções de deficiência e da vulnerabilidade associada a esta condição, debatendo sobre a relação retroativa entre a deficiência e a vulnerabilidade às violências. Entretanto, por mais que a vulnerabilidade de PcD seja apontada nos artigos teóricos, esta vulnerabilidade não foi empiricamente investigada nas pesquisas de campo.

Ainda há mais pesquisas a se realizar e áreas do conhecimento a se desbravar, o campo científico brasileiro demanda de análises estatísticas das notificações de violência exclusivamente das pessoas com deficiência, com comparação destes achados às notificações da população típica, além de estudos de casos de $\mathrm{PcD}$ vítimas de violência sexual e pesquisas de campo que debatam empiricamente sobre a vulnerabilidade que este público tem em relação às violências, relacionando os dados com as discussões teóricas da área da educação, dos estudos de gênero e dos movimentos feministas. Também se faz necessários programas de intervenção e prevenção de violências. Espera-se que este artigo tenha contribuído para o 
entendimento do campo científico brasileiro atual e possibilitado novas áreas de pesquisa e de estudos que ainda não foram contemplados.

AGRADECIMENTOS: Agradecemos ao Conselho Nacional de Desenvolvimento Científico e Tecnológico (CNPQ) pelo financiamento desta pesquisa.

\section{REFERÊNCIAS}

ABRAÇA. Manifesto: sou autista, tenho direito ao meu próprio corpo. Associação Brasileira para Ação por Direitos das Pessoas com Autismo. 2016. Disponível em:

http://abraca.autismobrasil.org/manifestocampanha2017/. Acesso em 13 set. 2019.

ASSIS, S. G. et al. Notificações de violência doméstica, sexual e outras violências contra crianças no Brasil. Ciênc. saúde coletiva, Rio de Janeiro, v. 17, n. 9, p. 2305-2317, 2012.

AVANCI, J. Q.; PINTO, L. W.; ASSIS, S. G. Atendimento dos casos de violência em serviços de urgência e emergência brasileiros com foco nas relações intrafamiliares e nos ciclos de vida. Ciênc. saúde coletiva, Rio de Janeiro, v. 22, n. 9, p. 2825-2840, 2017.

BASTOS, O. M.; DESLANDES, S. F. Sexualidade e deficiência intelectual: narrativas de pais de adolescentes. Physis, Rio de Janeiro, v. 22, n. 3, p. 1031-1046, 2012.

BISOL, C.; SPERB, T. M. Discursos sobre a surdez: deficiência, diferença, singularidade e construção de sentido. Psic.: Teor. e Pesq., Brasília, v. 26, n. 1, p. 07-13, 2010.

BRANDAO, E. R. Métodos contraceptivos reversíveis de longa duração no Sistema Único de Saúde: o debate sobre a (in)disciplina da mulher. Ciênc. saúde coletiva, Rio de Janeiro, v. 24, n. 3 , p. $875-879,2019$.

BRASIL. Lei n. 8.742, de 7 de dezembro de 1993. Dispõe sobre a organização da Assistência Social e dá outras providências. Diário Oficial da União: Seção 1, Brasília, DF, p. 18769, 08 dez. 1993. PL 4100/1993.

BRASIL. Lei n. 12.015, de 7 de agosto de 2009. Altera o Título VI da Parte Especial do Decreto-Lei n ${ }^{\circ}$ 2.848, de 7 de dezembro de 1940 - Código Penal, e o art. $1^{\circ}$ da Lei ${ }^{\circ}$ 8.072, de 25 de julho de 1990, que dispõe sobre os crimes hediondos, nos termos do inciso XLIII do art. $5^{\circ}$ da Constituição Federal e revoga a Lei $n^{\circ} 2.252$, de $1^{\circ}$ de julho de 1954, que trata de corrupção de menores. Diário Oficial da União: Seção 1, Brasília, DF, p. 01, 10 ago. 2009. PL 4850/2005.

BRASIL. Ministério da Saúde. Linha de cuidado para a atenção integral à saúde de crianças, adolescentes e suas famílias em situação de violências: orientação para gestores e profissionais de saúde. 1. ed. Brasília, DF: Ministério da Saúde, 2010. 104 p. 
BRASIL. Secretaria de Direitos Humanos da Presidência da República. Secretaria Nacional de Promoção dos Direitos da Pessoa com Deficiência. Cartilha do Censo 2010. Brasília, DF: SDH-PR/SNPD; 2012.

BRASIL. Lei n. 13.146, de 6 de julho de 2015. Institui a Lei Brasileira de Inclusão da Pessoa com Deficiência (Estatuto da Pessoa com Deficiência). Diário Oficial da União: Seção 1, Brasília, DF, p. 02, 07 jul. 2015.

CAMPOS, C. H.; SEVERI, F. C. Violência contra mulheres e a crítica jurídica feminista: breve análise da produção acadêmica brasileira. Rev. Direito Práx., Rio de Janeiro, v. 10, n. 2, p. 962-990, 2019.

CAMPOS, G. W. S. SUS: o que e como fazer? Ciênc. saúde coletiva, Rio de Janeiro, v. 23, n. 6, p. 1707-1714, 2018.

CARDOZO, P. S. Pessoas com deficiência e o protagonismo nos movimentos sociais.

Revista de Iniciação Científica, v. 15, n. 1, p. 39-54, 2017.

CAVALCANTE, F. G.; MINAYO, M. C. S. Representações sociais sobre direitos e violência na área da deficiência. Ciênc. saúde coletiva, Rio de Janeiro, v. 14, n. 1, p. 57-66, 2009.

CAVALCANTE, P.; RIBEIRO, B. B. O Sistema Único de Assistência Social: resultados da implementação da política nos municípios brasileiros. Rev. Adm. Pública, Rio de Janeiro, v. 46, n. 6, p. 1459-1477, 2012.

COSTA, A. B.; ZOLTOWSKI, A. P. C. Como escrever um artigo de revisão sistemática. In: KOLLER, S. H., COUTO, M. C. P. P., HOHENDORFF, J. V. (org.). Manual de produção científica. Porto Alegre, RS: Penso, 2014.

EICKMANN, S. H.; EMOND, A. M.; LIMA, M. Avaliação do desenvolvimento infantil: além do neuromotor. J. Pediatr. (Rio J.), Porto Alegre, v. 92, n. 3, supl. 1, p. 71-83, 2016.

GODINHO, C. C. P. S. et al. A violência no ambiente universitário. Rev Bras Promoç Saúde, v. 31, n. 4, p. 1-8, out./dez. 2018.

JACCOUD, L.; BICHIR, R.; MESQUITA, A. C. O SUAS na proteção social brasileira: transformações recentes e perspectivas. Novos estud. CEBRAP, São Paulo, v. 36, n. 2, p. 37 $53,2017$.

MALTA, D. C. et al. A ocorrência de causas externas na infância em serviços de urgência: aspectos epidemiológicos, Brasil, 2014. Ciênc. saúde coletiva, Rio de Janeiro, v. 21, n. 12, p. 3729-3744, 2016.

MASCARENHAS, M. D. M. et al. Violência contra a pessoa idosa: análise das notificações realizadas no setor saúde - Brasil, 2010. Ciênc. saúde coletiva, Rio de Janeiro, v. 17, n. 9, p. 2331-2341, 2012.

MELLO, A. G.; NUERNBERG, A. H. Gênero e deficiência: interseções e perspectivas. Rev. Estud. Fem., Florianópolis, v. 20, n. 3, p. 635-655, 2012. 
MENDES, M. J. G. DENARI, F. E. Deficiência e sexualidade: uma análise bibliométrica. Revista Ibero-Americana de Estudos em Educação, Araraquara, v. 14, n. esp. 2, p. 13571354, jul. 2019.

MINAYO, M. C. S. et al. Institucionalização do tema da violência no SUS: avanços e desafios. Ciênc. saúde coletiva, Rio de Janeiro, v. 23, n. 6, p. 2007-2016, 2018.

MORAES, S. P.; VITALLE, M. S. S. Direitos sexuais e reprodutivos na adolescência: interações ONU-Brasil. Ciênc. saúde coletiva, Rio de Janeiro, v. 20, n. 8, p. 2523-2531, 2015.

MOREIRA, M. C. N. et al. Violência contra crianças e adolescentes com deficiência: narrativas com conselheiros tutelares. Ciênc. Saúde coletiva, Rio de janeiro, v. 19, n. 9, p. 3869-3878, 2014.

NASCIMENTO, A. F.; DESLANDES, S. F. A construção da agenda pública brasileira de enfrentamento da violência sexual infanto-juvenil. Physis, Rio de Janeiro, v. 26, n. 4, p. 11711191, 2016.

NEVES-SILVA, P.; PRAIS, F. G.; SILVEIRA, A. M. Inclusão da pessoa com deficiência no mercado de trabalho em Belo Horizonte, Brasil: cenário e perspectiva. Ciênc. saúde coletiva, Rio de Janeiro, v. 20, n. 8, p. 2549-2558, 2015.

NICOLAU, S. M.; SCHRAIBER, L. B.; AYRES, J. R. C. M. Mulheres com deficiência e sua dupla vulnerabilidade: contribuições para a construção da integralidade em saúde. Ciênc. saúde coletiva, Rio de Janeiro, v. 18, n. 3, p. 863-872, 2013.

OLIVEIRA, T. G. Feministas ressignificando o direito: desafios para aprovação da Lei Maria da Penha. Rev. Direito Práx., Rio de Janeiro, v. 8, n. 1, p. 616-650, 2017.

OMS. ORGANIZAÇÃO MUNDIAL DA SAÚDE. Relatório mundial sobre a deficiência. Trad. Lexicus Serviços Lingüísticos. São Paulo, SP: OMS, The World Bank, 2011.

OMS. ORGANIZAÇÃO MUNDIAL DA SAÚDE. World report on violence and health. Geneva: OMS, 2002.

OTTONI, A. C. V.; MAIA, A. C. B. Considerações sobre a sexualidade e educação sexual de pessoas com Transtorno do Espectro Autista. Revista Ibero-Americana de Estudos em Educação, Araraquara, v. 14, n. esp. 2, p. 1265-1283, jul. 2019.

PLATT, V. B. et al. Violência sexual contra crianças: autores, vítimas e consequências. Ciênc. saúde coletiva, Rio de Janeiro, v. 23, n. 4, p. 1019-1031, 2018.

POLANCZYK, G. et al. Violência sexual e sua prevalência em adolescentes de Porto Alegre, Brasil. Rev. Saúde Pública, São Paulo, v. 37, n. 1, p. 8-14, 2003.

RATES, S. M. M. et al. Violência infantil: uma análise das notificações compulsórias, Brasil 2011. Ciênc. saúde coletiva, Rio de Janeiro, v. 20, n. 3, p. 655-665, 2015. 
SAMPAIO, R. F.; MANCINI, M. C. Estudos de revisão sistemática: um guia para síntese criteriosa da evidência científica. Revista brasileira de fisioterapia, v. 11, n. 1, p. 83-89, 2007.

SANCHES, L. C. et al. Violência sexual infantil no Brasil: uma questão de saúde pública. Revista Iberoamericana de Bioética, n. 9, p. 1-13, 2019.

SILVA, M. J. F. et al. A promoção de saúde pública a grupos vulneráveis como forma de extensão universitária e compromisso social. Extensão em Foco, n. 19, 2019.

SIMÕES, J. Sobre gramáticas emocionais e violência sexual. Notas a partir de dois casos de interrupção legal de gestação realizados por mulheres com deficiência intelectual. Anuário Antropológico, v. 44, n. 1, 2019.

SOUTO, R. M. C. V. et al. Perfil epidemiológico do atendimento por violência nos serviços públicos de urgência e emergência em capitais brasileiras, Viva 2014. Ciênc. saúde coletiva, Rio de Janeiro, v. 22, n. 9, p. 2811-2823, 2017.

SOUTO, R. Q. et al. Violência sexual contra mulheres portadoras de necessidades especiais: perfil da vítima e do agressor. Cogitare Enfermagem, v. 17, n. 1, 2012.

TOMAZ, R. V. V. et al. Políticas públicas de saúde para deficientes intelectuais no Brasil: uma revisão integrativa. Ciênc. saúde coletiva, Rio de Janeiro, v. 21, n. 1, p. 155-172, 2016.

UNFPA. Women and young persons with disabilities: guidelines for providing rights-based and gender-responsive services to address gender-based violence and sexual and reproductive health and rights. United Nations Population Fund., nov. 2018a.

UNFPA. Young persons with disabilities: global study on ending gender -based violence, and realising sexual and reproductive health and rights. United Nations Population Fund., jul. $2018 b$.

VILAÇA, T. Metodologias de ensino na educação em sexualidade: desafios para a formação contínua. Revista Ibero-Americana de Estudos em Educação, Araraquara, v. 14, n. 2, p. 1500-1537, jul. 2019.

VILLELA, W. V.; LAGO, T. Conquistas e desafios no atendimento das mulheres que sofreram violência sexual. Cad. Saúde Pública, Rio de Janeiro, v. 23, n. 2, p. 471-475, 2007. 


\section{Como referenciar este artigo}

MENDES, M. J. G.; DENARI, F. E. Violência sexual contra pessoas com deficiência nos últimos 10 anos: uma revisão sistemática. Doxa: Rev. Bras. Psico. E Educ., Araraquara, v. 22, n. $00, \quad$ e021013, 2021. e-ISSN: 2594-8385. DOI: https://doi.org/10.30715/doxa.v22i00.15335

Submetido em: 29/07/2021

Revisões requeridas em: 10/08/2021

Aprovado em: 15/09/2021

Publicado em: 01/10/2021 